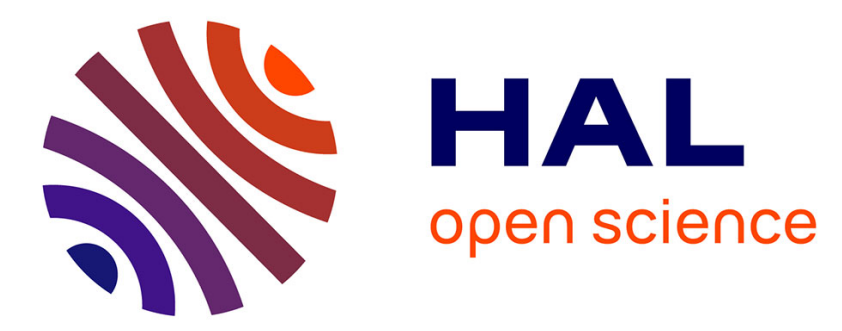

\title{
How does the never-dried state influence the swelling and dissolution of cellulose fibres in aqueous solvent?
}

Monica Spinu, Nuno dos Santos, Nicolas Le Moigne, Patrick Navard

\section{To cite this version:}

Monica Spinu, Nuno dos Santos, Nicolas Le Moigne, Patrick Navard. How does the never-dried state influence the swelling and dissolution of cellulose fibres in aqueous solvent?. Cellulose, 2011, 18 (2), pp.247-256. 10.1007/s10570-010-9485-8 . hal-00573828

\section{HAL Id: hal-00573828}

https: / hal-mines-paristech.archives-ouvertes.fr/hal-00573828

Submitted on 8 Apr 2011

HAL is a multi-disciplinary open access archive for the deposit and dissemination of scientific research documents, whether they are published or not. The documents may come from teaching and research institutions in France or abroad, or from public or private research centers.
L'archive ouverte pluridisciplinaire HAL, est destinée au dépôt et à la diffusion de documents scientifiques de niveau recherche, publiés ou non, émanant des établissements d'enseignement et de recherche français ou étrangers, des laboratoires publics ou privés. 


\title{
How does the never-dried state influence the swelling and dissolution of cellulose fibres in aqueous solvent?
}

\author{
Monica Spinu, Nuno Dos Santos, Nicolas Le Moigne and Patrick Navard* \\ Mines ParisTech, CEMEF - Centre de Mise en Forme des Matériaux, CNRS \\ UMR 7635, BP 207, 1 Rue Claude Daunesse, F-06904 Sophia Antipolis Cedex, \\ France
}

The CEMEF is member of the European Polysaccharide Network of Excellence (EPNOE), www.epnoe.eu

* Author for correspondence. E-mail: patrick.navard@mines-paristech.fr; phone: 33(0)493957466. Fax: 33(0)492389752

\begin{abstract}
The swelling and dissolution capacity of dried and never-dried hardwood and softwood pulps and cotton linters was compared in two aqueous solvents, $N$ methylmorpholine- $N$-oxide (NMMO)-water at $90{ }^{\circ} \mathrm{C}$ with water contents ranging from 16 to $22 \%$ and $\mathrm{NaOH}$ - water at $-6{ }^{\circ} \mathrm{C}$ with $\mathrm{NaOH}$ contents ranging from 5 to $8 \%$. Swelling and dissolution mechanisms were observed by optical microscopy and dissolution efficiency was evaluated by recovering insoluble fractions. The results show a contrasted picture towards the effect of the never-dried state on the swelling and the dissolution capacity depending on the origin of the fibres and the type of aqueous solvent. In the case of NMMO - water, the presence of water within and around the fibre does not seem to favour dissolution initiation but after two hours of mixing the dissolution yield appears to be similar for either dried or never-dried state. The limiting factor for dissolution in NMMO - water is not the penetration of the solvent inside the cellulose fibres, but only the local concentration of NMMO molecules around the fibre. For $\mathrm{NaOH}$ - water, both optical microscopy observations on individual fibres and dissolution yield measurements show that the never-dried state is more reactive for softwood pulps and cotton linters and has no significant effect on hardwood pulps. In this case, the local decrease of solvent strength is counteracted by the opening of the structure in the never-dried state which should enable the $\mathrm{Na}^{+}$hydrated ions to penetrate easier.
\end{abstract}

Keywords. Cellulose fibres; swelling; dissolution; never-dried state; $N$ methylmorpholine-N-oxide; sodium hydroxide 


\section{Introduction}

Wood is a porous material which contains large amounts of free and bound water, up to 50-60\% of the total weight of timber depending on many factors, including botanic origin and environmental conditions. After wood chipping and the various aqueous chemical treatments used to prepare cellulose pulp, wood cellulose fibres are wet, i.e. containing 50 to $70 \%$ of water. For integrated pulp and paper or dissolving pulp and regenerated cellulose mills, these wet or never-dried fibres offer the advantage of being very flexible and easily conformable, as compared to the same fibres having been dried. For use in non integrated mills, fibres need to be dried before they are shipped to customers.

Never-dried fibres have several key properties different from dried fibres. They are in a swollen and more accessible state. For example, studies performed on fibres in a never-dried state showed that they can absorb much more chemicals than fibres in their dried state (Brännvall 2007; Gerber et al. 1999; Ibbett et al. 2007). After drying and rewetting, fibres change irreversibly their properties; the internal volume of the fibre shrinks resulting in a decrease of the water retention value (WRV). This phenomenon is due to changes that occur at the structural level and was named hornification by Jayme (1944). Robertson (1964) and Maloney (1997) showed further that besides drying and rewetting, hornification can also occur during wet pressing. Since the earliest observations of Jayme (1944), a lot of attempts have been made to explain the causes and the mechanisms involved in hornification. Most of the existing literature about hornification refers to cellulose fibres used in paper industry, this phenomenon having undesirable effects on paper strength properties. Thode et al. (1955) showed by dye adsorption experiments a reduction of surface area of sulphite pulps due to hornification. It was demonstrated further that the structural change responsible for hornification is the irreversible pores closure that occurs upon drying (Stone and Scallan 1968). By solute exclusion method, Stone and Scallan (1968) showed that the large and intermediate size pores (2 to $20 \mathrm{~nm}$ ) are reduced upon drying. Based on NMR studies, Maloney (1997) concluded that hornification induces the closure of larger pores. The larger pores within Kraft fibres were also considered by Park et al. (2006) and 
Wang (2006) as being the earliest to close upon drying. As discussed by Fernandes Diniz et al. (2004), the possibility to reverse hornification was also investigated by several authors.

A mechanism proposed to explain hornification is the reorganisation of the fibre cell wall structure. According to Clark (1978), when adjacent surfaces of cellulose and hemicelluloses previously separated come into contact upon drying, it results in the creation of additional crystalline zones that prevent the separation of the two surfaces. Oksanen et al. (1997) demonstrated further that the removal of xylan and glucomannan is responsible for the decrease of the WRV of dried kraft pulps and suggested that hemicelluloses present in the fibre pores and in the interfibrillar spaces hamper hornification. Many research teams mentioned "hydrogen bonding" as being the main mechanism responsible for the failure of pores to re-open when the fibres are dried and rewetted (Kato and Cameron 1999; Lindström 1986). An alternative crosslinking mechanism is supported by several workers. Back (1967) and Ruffini (1966) suggested that thermal crosslinking takes place through the formation of esters. This was supported further by Fernandes Diniz et al. (2004) who assumed that hornification is due to the formation of lactone bridges, i.e. cyclic ester between hydroxyl and carboxylic acid groups, between adjacent cellulose chains.

Differences between the never-dried and the dried states also occur for cotton fibres. In the boll, cotton fibres grow in a close water-containing system and they dry at the end of the growth, upon opening of the boll. Never-dried cotton fibres extracted from the bolls exhibits higher water absorbancy compared to dried ones. Besides, age (days after post-anthesis) is strongly influencing the properties of cotton fibres. Significantly higher contents of bound water were measured at early stages post-anthesis (Mizutani et al. 1999). Never-dried young cotton fibres indeed have thinner secondary walls and larger lumens which allow higher accumulations of bound water but involve weaker tensile strengths and lower crystallinities (Tsuji et al. 1992) as compared to older ones. Dried and never-dried fibres have thus different properties that influence their behaviour.

As known cellulose does not melt before it thermally degrades, this causes difficulties in its processing. Up to now, the only way to prepare a 
thermoplastic or highly soluble form of cellulose is to either derivative cellulose to materials like cellulose acetate, or to dissolve cellulose in suitable solvents, the latter being employed in film extrusion and fibre spinning. The solubility of native cellulose fibres is usually not very high, and complete dissolution up to the molecular level is very difficult to achieve (Röder and Morgenstern 1999); this is ascribed to limited pore accessibility, long chain length, high crystallinity, the presence of hydrogen bonds or influence of other molecules like hemicelluloses or lignin (Klemm et al. 1998). Cellulose substrates are often activated, i.e. submitted to various chemical, physical or mechanical treatments to increase their reactivity and solubility.

Dissolution is classically studied using dried fibres as the starting material. Synthesis of cellulose derivatives at the industrial scale is also usually achieved starting from the dried state. Since the structure and properties of never-dried fibres are different from dried fibres, the question we address here is whether the never-dried state of a fibre increases or decreases its solubility in an aqueous solvent. On one hand, the never-dried state is a more open state that should favour penetration of solvent and accessibility to cellulose chains. On the other hand, the presence of water inside and around the fibres should change locally the quality of aqueous solvents by diluting them and thus decreasing their strengths. This paper reports an investigation of the swelling and dissolution capacity of dried and never-dried wood cellulose and cotton linter fibres in two aqueous solvent solutions of $\mathrm{N}$-methylmorpholine- $\mathrm{N}$-oxide and $\mathrm{NaOH}$. Two complementary techniques will be used: firstly, observing the swelling and dissolution mechanisms by optical microscopy and secondly measuring the dissolution yield using a centrifugation method. The first method gives indications on the way cellulose fibres swell and dissolve but has the drawback of considering only a few fibres. The second method measures the average dissolution yield over several thousands of fibres. 


\section{Materials and Methods}

\section{Cellulose fibre samples}

Nine different dried or never-dried cellulose fibres were provided by several companies. Their botanic origin, treatment and main properties are listed in Table 1.

\section{Conditioning of the samples and drying procedure}

The never-dried pulps and the cotton linters were received in a bulk form packaged in sealed hermetic bags, while the dried wood pulps were received in the form of dried pulp sheets. In order to facilitate the processing of the dried fibres, the pulp sheets had to be disintegrated. The pulp was first soaked in water for 15 minutes, defibrillated with a disintegrator for 5 minutes at $500 \mathrm{rpm}$. After removing most of the water with a centrifuge, the pulp was acclimatized in a room with controlled atmosphere $\left(20^{\circ} \mathrm{C}\right.$ and $65 \%$ humidity), reaching a consistency of $\sim 93 \%$, then packaged in sealed hermetic bags. The initial moisture content of all samples before experiments was determined by measuring the weight of a sample portion before and after drying overnight in a vacuum oven at $70{ }^{\circ} \mathrm{C}$ and 50 mbar in presence of silica gel.

In order to study the influence of the water content, never-dried samples S-03, S-05, S-06 and S-07 were dried for different periods of time (from 0-70 minutes) in an air oven at constant temperature $\left(50^{\circ} \mathrm{C}\right)$. The water quantity was calculated by measuring the weight of the samples prior to drying and at different drying times and the samples were then directly packaged in sealed hermetic bags. The mass of sample as a function of time in an oven at $50{ }^{\circ} \mathrm{C}$ is given on Figure 1 for samples S-03, S-05, S-06 and S-07. This allows defining what are called partially-dried samples and dried samples, as shown on the Figure. In the never-dried and partially-dried state (from 0 to $30 \mathrm{~min}$ of drying), the samples still contain some amount of bound and free water, especially for the never-dried samples. In the completely dried state (after one hour of drying at $50{ }^{\circ} \mathrm{c}$ ), the samples contain only some bound water (Maloney et al. 1998; Nakamura et al. 1981). 


\section{Aqueous solvent systems}

Two aqueous solvents were used, $N$-methylmorpholine- $N$-oxide (NMMO) and sodium hydroxide $(\mathrm{NaOH})$ both mixed with distilled water. The mixtures based on NMMO with different water contents were prepared by adding distilled water to the anhydrous NMMO powder (97\% purity, provided by Sigma Aldrich). Four water concentrations were used, respectively $16 \%$, $18 \%, 20 \%$ and $22 \%$ (w/w). All dissolution experiments with NMMO-water were carried out at $90{ }^{\circ} \mathrm{C}$. The mixtures based on $\mathrm{NaOH}$ were prepared by mixing distilled water with $\mathrm{NaOH}$ (98\% purity, provided by Sigma Aldrich). Four different mixtures were prepared with $\mathrm{NaOH}$ concentrations of $5 \%, 6 \%$ and $8 \%$ w/w. All experiments with $\mathrm{NaOH}$ mixtures were carried out at $-5 \sim$ $6{ }^{\circ} \mathrm{C}$.

\section{Optical microscopy observations}

Optical microscopy observations were carried out after placing the cellulose fibres between two glass plates. The solvent was put in contact with the fibres by introducing it between the two plates by capillary forces. No agitation was applied to the system. The mechanisms of swelling and dissolution were observed in transmission mode using either a Metallux 3 (Leitz) or a Leica DM 4500P equipped with a Linkam TMS 91 and a Linkam TMS 94 hot/cryo stage respectively. Images were obtained with a high resolution 3-CCD camera (1360 x 1024 pixels) JVC KY-F75U, recording digitally the observations with the Archimed 5.5.1 software from Microvision Instruments. Swelling and dissolution trials were performed several times by different experimenters in order to check the reproducibility and the accuracy of the results.

\section{Dissolution yield measurements}

NaOH-water: $2 \mathrm{~g}$ of cellulose fibres (dry weight) were added to $66 \mathrm{~g}$ of distilled water, gently stirred and stored at $4{ }^{\circ} \mathrm{C}$ for 1 hour. The water content of the samples was taken into account when calculating the total amount of distilled water to be added. $132 \mathrm{~g}$ of $\mathrm{NaOH} 12 \%$ aqueous solution were prepared and stored in a ethylene glycol bath at $-6.1^{\circ} \mathrm{C}$ for 2 hours. Both preparations were mixed together, giving a solution of $1 \%$ cellulose in $8 \%$ 
$\mathrm{NaOH}$ aqueous solvent. The solutions were stirred using a rotary overhead mixer during 2 hours at $-6.1{ }^{\circ} \mathrm{C}$ and $\sim 1000 \mathrm{rpm}$. The resulting solutions were then centrifuged to separate by decantation the insoluble fraction from the clear solution fraction. The centrifugation was done at $9000 \mathrm{rpm}$ (equivalent to 9050 g) for 8 min with a Hettich Universal 320RHK centrifuge equipped with a $1620 \mathrm{~A}$ rotor and thermo-regulated with an external Julabo cryostat set at $0{ }^{\circ} \mathrm{C}$. The recovered insoluble fractions were washed with $1 \mathrm{~L}$ of distilled water in a sintered glass filter G3 and dried overnight in a vacuum oven at $70{ }^{\circ} \mathrm{C}$ and 50 mbar in presence of silica gel. After drying, the insoluble fractions were weighed and the dissolution yield, i.e. the amount of material contained in the clear solution fraction, determined.

NMMO-water: the same procedure was followed except that the solution was a $1 \%$ cellulose / NMMO - $18 \%$ of water $(\mathrm{w} / \mathrm{w})$ mixture. The total weight of the mixture including the cellulose sample was $50 \mathrm{~g}$, the temperature of mixing was $90{ }^{\circ} \mathrm{C}$ and the temperature of centrifugation was $75^{\circ} \mathrm{C}$.

\section{Results and discussions}

The dissolution of cellulose can be assessed through different complementary ways like looking at the state of dissolution by light scattering or NMR or measuring dissolution kinetics. An interesting method that can be applied to cellulose fibres is to look at the way the fibres are swelling and dissolving. With very good solvents as NMMO-water solutions containing $16 \%$ of water $(\mathrm{w} / \mathrm{w})$, the fibres are disintegrated into elongated fragments in a rather short time, with the subsequent dissolution of all the fragments (Cuissinat and Navard 2006a). When the quality of the solvent decreases (NMMO-water mixtures containing $20-22 \%$ of water (w/w)), the primary wall, if present, is not easily dissolved. The inner zones of the fibre dissolve first (Le Moigne et al. 2008; Le Moigne et al. 2010a) and the fibre adopts a balloon morphology. With time, the whole fibre dissolves. For poorer solvents, there is a ballooning morphology with dissolved cellulose inside, but the whole fibre does not dissolve and stays in this ballooned state. This was observed in the case of aqueous solutions containing $7.6 \%$ of $\mathrm{NaOH}$ at $-5{ }^{\circ} \mathrm{C}$ (Cuissinat and Navard 2006b). With a further decrease of solvent quality, the fibre swells slightly, swelling homogeneously without dissolving. This description of 
swelling and dissolution mechanisms as a function of solvent quality has a general character for fibres coming from different botanical sources and even for cellulose derivatives that have been prepared in a heterogeneous way (Cuissinat and Navard 2008; Cuissinat et al. 2008).

What will be investigated here is the influence of the water content of the fibre on the swelling and dissolution mechanisms, especially in the neverdried state. The main effect to be expected comes indeed from the never-dried state, where fibres are in a large "open" state. As written in the introductory part of this paper, chemicals easily penetrate the fibre when it is in the neverdried state. However, the presence of water within and around the fibres should decrease the quality of the solvent. We will examine whether the never-dried state improves the reactivity towards swelling and dissolution or not, at least in the two aqueous solvents that are considered here.

\section{Swelling and dissolution in NMMO-water}

The optical microscopy observations of the dried fibres in NMMO [16-22\%] water mixtures showed two mechanisms: fragmentation followed by full dissolution for the 16 and $18 \%$ water concentrations and ballooning followed by full dissolution for 20 and $22 \%$ water concentrations. These results are reported in Table 2 for the "D" case, i.e. dried fibres. As assessed by optical microscopy, NMMO - 16 and $18 \%$ water were good solvents for the four cellulose samples (S-03, S-05, S-06, S-07 after drying) with a fragmentation mechanism while NMMO- 20 and $22 \%$ water was not so good with a slower dissolution by ballooning.

At $16 \%$ water, the partially and never-dried state did not change the dissolution mechanism which was still fragmentation for all pulps. In NMMO 20 and $22 \%$ water, the optical observations of the partially and never-dried fibres showed that the dissolution mechanism was not affected by the presence of some water within and around the fibres which still dissolved by ballooning. An effect of the presence of water was visible for the intermediate concentration, NMMO - $18 \%$ water. In the dried state, only dissolution by fragmentation was observed, whereas both fragmentation and ballooning were observed in the partially-dried state for all pulps. In the never-dried state, both fragmentation and ballooning were observed for S-03 and S-05 pulps and 
fibres dissolved by ballooning for S-06 and S-07 pulps which means poorer dissolution for the latter samples as compared to S-03 and S-05 pulps. In NMMO - $18 \%$ water, there is thus a switch from the dissolution by fragmentation for dried fibres to the dissolution by ballooning for never-dried fibres (Figure 2a and 2b). Therefore, water within and around the fibre decreases the dissolution efficiency. It has to be noticed that the difference of behaviour between the never-dried S-03, S-05 and S-06, S-07 pulps illustrates the influence of the severity of the sulphite pre-treatment. The highest intrinsic viscosity pulps (S-06, S-07) were in fact digested at the highest kappa number which involved less degradation of the walls and the cellulose chains as compared to the two other pulps (S-03, S-05). Consequently, the dissolution is easiest for S-03 and S-05 pulps for which the original solid state is much more damaged as compared to S-06 and S-07 pulps.

Dissolution yield measurements after centrifugation were performed on solutions of never-dried softwood bleached sulphite pulp S-03 and dried S-04 in a NMMO - $18 \%$ water mixture. In the experimental protocol used for optical microscopy observations, the water brought by the never-dried fibres had no significant influence on the total amount of water, since only a few fibres were placed in a large amount of solvent. It was not the case for the preparation of the $1 \%$ cellulose solutions for subsequent dissolution yield measurements and care was exercised for taking into account the water brought by the never-dried fibres in the calculation of the total water content of the solvent. The temperature during mixing was $90{ }^{\circ} \mathrm{C}$ and the temperature of centrifugation was $75^{\circ} \mathrm{C}$ to prevent the crystallisation of the NMMO - water solvent. The dissolution yields determined after centrifugation and drying of the insoluble fractions were very similar, $93.7 \%$ and $92.1 \%$ for the neverdried (S-03) and the dried (S-04) samples respectively (Figure 3). Optical microscopy observations of the insoluble fractions showed some unswollen fibres and some others swollen by ballooning or swollen homogeneously (Figure 4).

To conclude, the dissolution initiation is slightly slowed down in the never-dried state as compared to the dried state, especially in NMMO - $18 \%$ water. It seems that the presence of water within and around the fibres pushes the dissolution mechanisms towards the one seen with a solvent containing a 
higher water content. It is recalled that the sequence of swelling and dissolution mechanisms can be classified into four main dissolution modes for wood and cotton fibres as a function of the quality of the solvent by using NMMO with various amounts of water (Cuissinat et al. 2006a). On the other hand, the dissolution yield measurements showed that after two hours of mixing in NMMO - $18 \%$ water, no significant influence of the never-dried state can be observed. The limiting factor for dissolution in NMMO - water is not the penetration of the solvent inside the cellulose fibre, which is supposed to be easier in the never-dried state. In NMMO aqueous solvent, the only influencing parameter is the local concentration of NMMO molecules around a fibre.

\section{Swelling and dissolution in $\mathrm{NaOH}$-water}

The swelling and dissolution of cellulose fibres in $8 \%, 6 \%$ and $5 \%$ $\mathrm{NaOH}$ aqueous solutions was measured with dried and never-dried pulps. The dissolution mechanisms observed by optical microscopy are described below.

In $\mathrm{NaOH} 8 \%$ - water upon cooling from $20{ }^{\circ} \mathrm{C}$ to $-6{ }^{\circ} \mathrm{C}$, the never-dried hardwood bleached sulphite pulp fibres (S-01) started swelling at around $10{ }^{\circ} \mathrm{C}$, this mechanism being more intense at $-4{ }^{\circ} \mathrm{C}$. The dried fibres $(\mathrm{S}-02)$ had a slightly slower swelling initiation than the never-dried fibres. In both cases, it was observed that the parenchyma cells were not affected by the solvent. Fibres which were highly fibrillated swelled very fast, while intact fibres showed slight swelling and ballooning in some dislocations. This can be explained by the fact that in these dislocations, the macrostructure of the fibre was deformed and damaged, allowing locally easy diffusion of the solvent into the fibre. The vessels unfolded and distended their structures but neither swelling nor dissolution were observed.

For softwood bleached sulphite pulp, in the never-dried state (S-03) at around $16^{\circ} \mathrm{C}$ the fibres started moving in space by distending themselves, and by a temperature of $\sim 10^{\circ} \mathrm{C}$, swelling by ballooning started (Figure 5a). For the dried fibres (S-04), the same was observed, but the phenomenon was slower. In both states, several fibres showed a large homogeneous swelling (Figure 5a) revealing the absence of primary wall as observed by Le Moigne and Navard (2010) for wood pulps and after the enzymatic peeling of the primary wall (Le Moigne et al. 2010b). As for hardwood, the parenchyma cells were not affected 
by this solvent system and the most intact fibres showed only slight swelling and ballooning localized in the dislocations.

Cotton linter fibres became highly swollen (Figure 5b) and ballooning was not as clearly seen as for wood pulps. Both never-dried (S-08) and dried fibres (S-09) started distending in space at $\sim{ }^{\circ} \mathrm{C}$, followed by swelling but without dissolution. These mechanisms started faster in the never-dried state (S-08).

By decreasing the $\mathrm{NaOH}$ concentration to $6 \%$, the same swellind and dissolution patterns as with $8 \% \mathrm{NaOH}$ aqueous solution were observed for all samples but they occured more slowly. With a concentration of $5 \% \mathrm{NaOH}$, the solvent system was not able to achieve any swelling or solvating activity for the samples used (except in the case of extremely fibrillated and thin fibres).

The following main observations and conclusions can be drawn (see Table 3). The fibres start swelling and ballooning at about $10^{\circ} \mathrm{C}$ for wood pulps and about $0{ }^{\circ} \mathrm{C}$ for cotton linters upon cooling the fibre-solvent mixture. The parenchyma cells, present in hardwood, are not affected by the solvent and the vessels are distending, showing an apparent swelling, but do not dissolve. The mechanisms of swelling are different when comparing softwood and cotton linter fibres, the ballooning being more evident in softwood fibres, while for cotton linters the swelling is homogeneous along large sections (Figure 5a and b). In contrast with NMMO-water solvents, the never-dried state improves significantly the swelling initiation of the softwood fibres and the cotton linters in $\mathrm{NaOH}$-water.

To complement these results, dissolution yield measurements were performed for each sample in an $8 \% \mathrm{NaOH}$ aqueous solution. The results are shown on Figure 3. They are in agreement with the optical microscopy observations. No significant effect is measured for hardwood pulps S-01 and S02, possibly due to their more compact structure which is less accessible to water and also less reactive to $\mathrm{NaOH}$ - water mixture. For softwood pulps and cotton linters, the dissolution yield was significantly higher for the never-dried state than the dried state. It has to be emphasized that the clear solution fraction recovered after centrifugation should be composed of cellulose and hemicelluloses, the latter being present in relatively low contents in sulphite pulps. 
One hypothesis to explain the highest swelling and dissolution capacity of never-dried softwood pulps and cotton linters in $6-8 \% \mathrm{NaOH}$ solvent is that $\mathrm{Na}^{+}$hydrates have primary and secondary solvation cages so large (Kunze et al. 1985, Yamashiki et al. 1988) that they cannot penetrate the smallest fibre pores, except if the structure is more open and full of water, as it occurs in the never-dried state. The decrease of solvent strength due to the local excess of water within and around the fibres is thus not preponderant in $\mathrm{NaOH}$-water solvent unlike the NMMO-water solvent.

\section{Conclusions}

Our results show a contrasted picture towards the effect of the neverdried state on the swelling and dissolution capacity depending on the origin of the cellulose fibres and the type of aqueous solvent. The never-dried state, although being more accessible, is not necessarily the best state to swell and dissolve cellulose fibres. In the case of NMMO - water, the never dried-state does not seem to favour dissolution initiation but has no influence on the final dissolution yield. If correct, it means that the limiting factor for dissolution in NMMO - water is not the penetration of the solvent inside the cellulose fibre. What is acting first is the fact that water around and inside the fibre dilutes the NMMO - water system locally, decreasing then its solvating activity. In NMMO aqueous solvent, the only influencing parameter is thus the local concentration of NMMO molecules which seem to be able to approach easily cellulose backbones, whatever the state of the structure of cellulose fibres, i.e. open or not. In the case of $\mathrm{NaOH}$-water, both optical microscopy observations on individual fibres and dissolution yield measurements show that the neverdried state is more reactive for softwood pulps and cotton linters and has no effect on hardwood pulps. We postulate that one of the limiting factor for swelling and dissolution in $\mathrm{NaOH}-$ water is the size of the $\mathrm{Na}^{+}$hydrated ions, too large to penetrate inside the small pores of dried cellulose fibres, but able to penetrate easier within fibres in the never-dried state which offers a more open structure. 
Acknowledgements. The authors want to thank Borregaard, Lenzing AG and Milouban LTD for providing the samples. NLM thanks the Carnot Mines institute for its financial support. NDS thanks Viskase ${ }^{\circledR}$, Spontex ${ }^{\circledR}$, Sappi, Tembec, Inc. and Lenzing, AG for financial support and vTI/Universität Hamburg for academic support.

\section{References}

Back EL (1967) Thermal auto-crosslinking in cellulose material. Pulp Pap Mag Can 68:T165T171

Brännvall E (2007) Aspects on strength delivery and higher utilisation of the strength potential of softwood kraft pulp fibres. PhD dissertation, KTH Royal Institute of Technology, Stockholm, Sweden

Clark J d'A (1978) Pulp technology and treatment for paper. Miller Freeman Publications Inc., San Francisco

Cuissinat C, Navard P (2006a) Swelling and dissolution of cellulose Part 1: Free floating cotton and wood fibres in $N$-Methylmorpholine- $N$-oxide-water mixtures. Macromol Symp 244:1-18

Cuissinat C, Navard P (2006b) Swelling and dissolution of cellulose, Part II: free floating cotton and wood fibres in $\mathrm{NaOH}$ water-additives systems. Macromol Symp 244:19-30

Cuissinat C, Navard P (2008) Swelling and dissolution of cellulose, Part III: Plant fibres in aqueous systems. Cellulose 15:67-74

Cuissinat C, Navard P, Heinze T (2008) Swelling and dissolution of cellulose, Part V: free floating cellulose derivatives fibres in aqueous systems and ionic liquid. Cellulose 15:75-80

Fernandes Diniz JMB, Gil MH, Castro JAAM (2004) Hornification - its origin and interpretation in wood pulps. Wood Sci Technol 37:489-494

Gerber PJ, Heitmann JA, Joyce TW, Buchert J, Siika-aho M (1999) Adsorption of hemicellulases onto bleached kraft fibers. J Biotechnol 67:67-75

Ibbett RN, Kaenthong S, Phillips DAS, Wilding MA (2007) Solute adsorption and exclusion studies of the structure of never-dried and re-wetted cellulosic fibres. J Mater Sci 42:68096818

Jayme G (1944) Mikro-quellungsmessungen an zellstoffen. Wo- chenbl Papierfabr 6:187-194

Kato KL, Cameron RE (1999) A review of the relationship between thermally-accelerated ageing of paper and hornification. Cellulose 6:23-40

Klemm D, Phillipp B, Heinze T, Heinze U, Wagenknecht W (1998) Comprehensive cellulose chemistry, Volume 1: Fundamentals and analytical methods. Wiley VCH, Weinheim

Kunze J, Ebert A, Lang H, Philipp B (1985) Na-NMR spektroskopische untersuchungen zur hydratation von natriumhydroxid in wäbriger lösung. Z Phys Chemie 266:49-58

Le Moigne N, Montes E, Pannetier C, Höfte H, Navard P (2008) Gradient in dissolution capacity of successively deposited cell wall layers in cotton fibres. Macromol Symp 262:65-71 
Le Moigne N, Navard P (2010) Dissolution mechanisms of wood cellulose fibres in NaOHwater. Cellulose 17:31-45

Le Moigne N, Bikard J, Navard P (2010a) Rotation and contraction of native and regenerated cellulose fibers upon swelling and dissolution: the role of morphological and stress unbalances. Cellulose 17:507-519

Le Moigne N, Jardeby K, Navard P (2010b) Structural changes and alkaline solubility of wood cellulose fibers after enzymatic peeling treatment. Carbohydr Polym 79:325-332

Lindström T (1986) The porous lamellar structure of the cell wall. In: Bristow JA, Kolseth P (Eds) Paper, structure and properties. Marcel Dekker, New York, pp 99-109

Maloney TC, Li TQ, Weise U, Paulapuro H (1997) Intra and inter-fibre pore closure in wet pressing. Appita J 50:301-306

Maloney TC, Johansson T, Paulapuro H (1998) Removal of water from the cell wall during drying. Paper Technol 39:39-47

Mizutani C, Inagaki H, Bertoniere NR (1999) Water absorbancy of never-dried cotton fibers. Cellulose 6:167-176

Nakamura K, Hatakeyama T, Hatakeyama H (1981) Studies on bound water of cellulose by differential scanning calorimetry. Text Res J, 51:607-613

Oksanen T, Buchert J, Viikari L (1997) The role of hemicelluloses in the hornification of bleached kraft pulps. Holzforschung 51:355-360

Park S, Venditti RA, Jameel H, Pawlak JJ (2006) Changes in pore size distribution during the drying of cellulose fibers as measured by differential scanning calorimetry. Carbohyd Polym 66:97-103

Robertson AA (1964) Some observations on the effects of drying papermaking fibres. Pulp Pap Mag Can 65:T161-T168

Röder T, Morgenstern B (1999) The influence of activation on the solution state of cellulose dissolved in $N$-methylmorpholine- $N$-oxide-monohydrate. Polymer 40:4143-4147

Ruffini G (1966) Improvement in bonding of wood pulps by the presence of acidic groups. Svensk Papperstidn 69:72-76

Stone JE, Scallan AM (1968) A structural model for the cell wall of water-swollen wood pulp fibres based on their accessibility to macromolecules. Cell Chem Technol 2:343-358

Thode EF, Chase AJ, Hu Y (1955) Dye adsorption on wood pulp, IV. Note on effect of drying of pulp on specific dye adsorption. Tappi 38:88-89

Tsuji W, Nakao T, Hirai A, Horii F (1992) Properties and structure of never-dried cotton fibers. III: Cotton fibers from bolls in early stages of growth. J Appl Polym Sci 45:299-307

Yamashiki T, Kamide K, Okajima K, Kowasaka K, Matsui T, Fukase H (1988) Some characteristic features of dilute aqueous alkali solutions of specific alkali concentration (2,5mol/l) which possess maximum solubility power against cellulose. Polym J 20:447-457

Wang X (2006) Improving the papermaking properties of kraft pulp by controlling hornification and internal fibrillation. $\mathrm{PhD}$ dissertation, Helsinki University of Technology, Reports Series A26, Espoo, Finland 
Table 1: List of cellulose fibres used in the study

\begin{tabular}{|l|l|c|c|c|l|}
\hline Name & Description & State & Moisture (\%) & Intrinsic viscosity (ml/g) & \multicolumn{1}{|c|}{ Source } \\
\hline S-01 & Hardwood (beech) bleached sulfite pulp & never-dried & 52 & 530 & Lenzing AG \\
\hline S-02 & Hardwood (beech) bleached sulfite pulp & dried & 7 & 530 & Lenzing AG \\
\hline S-03 & Softwood (spruce) bleached sulfite pulp & never-dried & 75 & 620 & Borregaard Schweiss AG \\
\hline S-04 & Softwood (spruce) bleached sulfite pulp & dried & 6 & 620 & Borregaard Schweiss AG \\
\hline S-05 & Softwood (spruce) bleached sulfite pulp & never-dried & 70 & 750 & Borregaard Norway \\
\hline S-06 & Softwood (spruce) bleached sulfite pulp & never-dried & 70 & 900 & Borregaard Norway \\
\hline S-07 & Softwood (spruce) bleached sulfite pulp & never-dried & 70 & 1700 & Borregaard Norway \\
\hline S-08 & Cotton linter & never-dried & 35 & 700 & Milouban (M.C.P.) LTD \\
\hline S-09 & Cotton linter & dried & 7 & 700 & Milouban (M.C.P.) LTD \\
\hline
\end{tabular}


Table 2: Summary of the mechanisms responsible for the dissolution of the fibres in NMMO with water mixtures - ND refers to never-dried state, PD to the partially-dried state and D to the completely dried state. "ball" refers to the ballooning phenomenon and "frag" refers to the fragmentation phenomenon. "disso" is for dissolution.

\begin{tabular}{|c|c|c|c|c|}
\hline Sample & NMMO - $16 \%$ water & NMMO - $18 \%$ water & NMMO - $20 \%$ water & NMMO - $22 \%$ water \\
\hline S-03 & $\begin{array}{l}\text { ND : frag \& disso } \\
\text { D : frag \& disso }\end{array}$ & $\begin{array}{l}\text { ND : ball or frag \& disso } \\
\text { PD : ball or frag \& disso } \\
\text { D : frag \& disso }\end{array}$ & $\begin{array}{l}\mathrm{ND}: \text { ball \& disso } \\
\mathrm{PD}: \text { ball \& disso } \\
\mathrm{D}: \text { ball \& disso }\end{array}$ & $\begin{array}{l}\text { ND: ball \& disso } \\
\text { PD : ball \& disso } \\
\text { D : ball \& disso }\end{array}$ \\
\hline$\overline{S-05}$ & $\begin{array}{l}\text { ND : frag \& disso } \\
D \text { : frag \& disso }\end{array}$ & $\begin{array}{l}\text { ND : ball or frag \& disso } \\
\text { PD : ball or frag \& disso } \\
\text { D : frag \& disso }\end{array}$ & $\begin{array}{l}\mathrm{ND}: \text { ball \& disso } \\
\mathrm{PD}: \text { ball \& disso } \\
\mathrm{D}: \text { ball \& disso }\end{array}$ & $\begin{array}{l}\text { ND: ball \& disso } \\
\text { PD : ball \& disso } \\
\text { D : ball \& disso }\end{array}$ \\
\hline$\overline{S-06}$ & $\begin{array}{l}\text { ND : frag \& disso } \\
\text { D : frag \& disso }\end{array}$ & $\begin{array}{l}\text { ND: ball \& disso } \\
\text { PD : ball or frag \& disso } \\
\text { D : frag \& disso }\end{array}$ & $\begin{array}{l}\text { ND: ball \& disso } \\
\text { PD : ball \& disso } \\
\text { D : ball \& disso }\end{array}$ & $\begin{array}{l}\text { ND: ball \& disso } \\
\text { PD : ball \& disso } \\
\text { D : ball \& disso }\end{array}$ \\
\hline$\overline{\mathrm{S}-07}$ & $\begin{array}{l}\text { ND : frag \& disso } \\
\text { D : frag \& disso }\end{array}$ & $\begin{array}{l}\text { ND: ball \& disso } \\
\text { PD : ball or frag \& disso } \\
\text { D : frag \& disso }\end{array}$ & $\begin{array}{l}\text { ND: ball \& disso } \\
\text { PD : ball \& disso } \\
\text { D : ball \& disso }\end{array}$ & $\begin{array}{l}\text { ND: ball \& disso } \\
\text { PD : ball \& disso } \\
\text { D : ball \& disso }\end{array}$ \\
\hline
\end{tabular}


Table 3: Summary of the mechanisms responsible for the swelling of the fibres in $\mathrm{NaOH}$ - water mixtures - ND refers to never-dried state and $\mathrm{D}$ to the completely dried state. "swell" refers to swelling and "ball" refers to the ballooning phenomenon. In all cases, swelling initiation was slower in the dried state.

\begin{tabular}{|c|c|c|c|}
\hline Sample & $\mathrm{NaOH}-8 \%$ Water & $\mathrm{NaOH}$ - 6\% Water & $\mathrm{NaOH}-5 \%$ Water \\
\hline $\begin{array}{l}\mathbf{S}-01 \\
(\mathrm{ND})\end{array}$ & $\begin{array}{c}\text { low swell } \\
\text { \& low ball } \\
\text { swelling initiation }(+)\end{array}$ & \multirow{6}{*}{$\begin{array}{c}\text { Same as water }-8 \% \mathrm{NaOH} \\
\text { with slower swelling } \\
\text { initiation }\end{array}$} & \multirow{6}{*}{$\begin{array}{l}\text { No swelling except for } \\
\text { extremely fibrillated and } \\
\text { thin fibres }\end{array}$} \\
\hline $\begin{array}{l}\text { S-02 } \\
\text { (D) }\end{array}$ & $\begin{array}{c}\text { low swell } \\
\text { \& low ball } \\
\text { swelling initiation (-) }\end{array}$ & & \\
\hline $\begin{array}{l}\mathbf{S - 0 3} \\
(\mathrm{ND})\end{array}$ & $\begin{array}{c}\text { large homogeneous swell } \\
\text { \& ball } \\
\text { swelling initiation }(+)\end{array}$ & & \\
\hline $\begin{array}{l}\text { S-04 } \\
\text { (D) }\end{array}$ & $\begin{array}{l}\text { large homogeneous swell } \\
\text { \& ball } \\
\text { swelling initiation (-) }\end{array}$ & & \\
\hline $\begin{array}{l}\mathbf{S - 0 8} \\
(\mathrm{ND})\end{array}$ & $\begin{array}{c}\text { large homogeneous swell } \\
\text { \& low ball } \\
\text { swelling initiation }(+)\end{array}$ & & \\
\hline $\begin{array}{l}\text { S-09 } \\
\text { (D) }\end{array}$ & $\begin{array}{c}\text { large homogeneous swell } \\
\text { \& low ball } \\
\text { swelling initiation (-) }\end{array}$ & & \\
\hline
\end{tabular}




\section{Captions for Figures}

Fig. 1 Evolution of the weight of softwood samples S-03, S-05, S-06 and S-07 as a function of time upon drying in an air oven at $50{ }^{\circ} \mathrm{C}$.

Fig. 2 Observations by optical microscopy of (a) dissolution by fragmentation in NMMO - $18 \%$ water of a softwood fibre (S-06) in the dried state; (b) dissolution by ballooning in NMMO - $18 \%$ water of a softwood fibre (S-06) in the never-dried state.

Fig. 3 Dissolution yields of the never-dried and dried pulps in $\mathrm{NaOH} 8 \%$ water and NMMO - 18\% water. HBSP stands for Hardwood Bleached Sulphite Pulp (samples S-01 and S-02), SBSP for Softwood Bleached Sulphite Pulp (samples S-03 and S-04) and CL for Cotton Linters (samples S-08 and S-09).

Fig. 4 Observations by optical microscopy of the undissolved fraction obtained after centrifugation of a solution of never-dried S-03 pulp in NMMO - 18\% water.

Fig. 5 Observations by optical microscopy of (a) never-dried softwood fibres (S-03) and (b) dried cotton linter fibres (S-08) swelled in $\mathrm{NaOH} 8 \%$ - water. A homogeneous swelling is seen for cotton linter fibres while the ballooning is more pronounced for the softwood fibres. A highly homogeneously swollen softwood fibre is also visible (black arrow). 


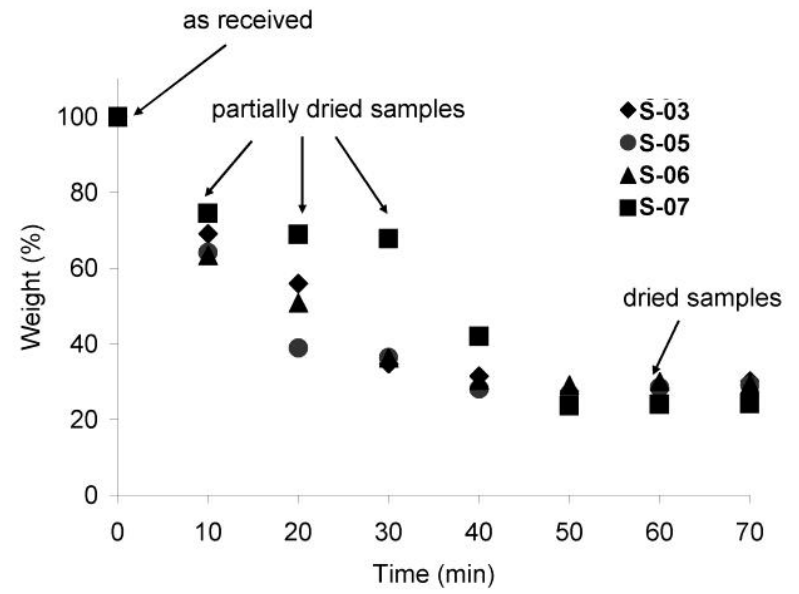

Fig. 1

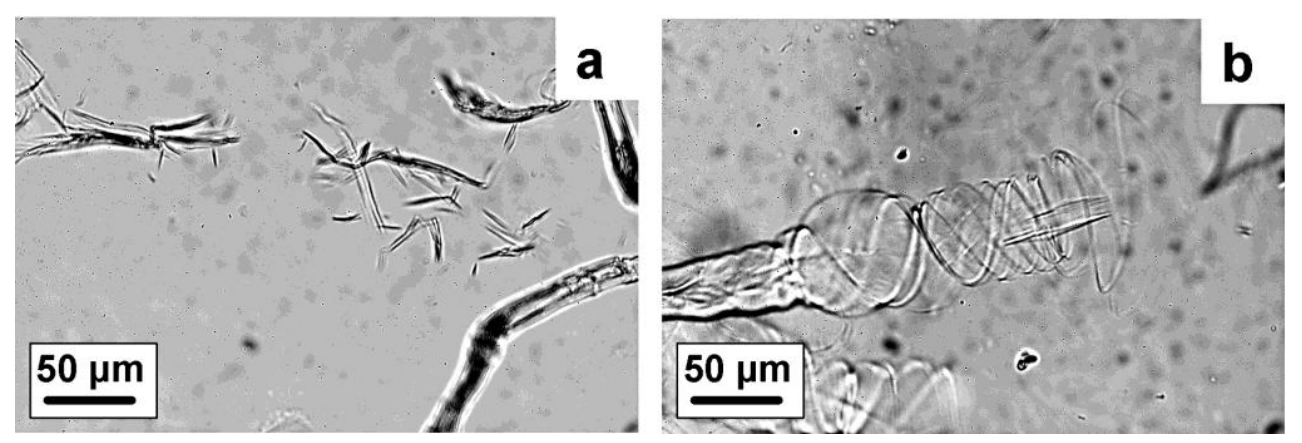

Fig. 2

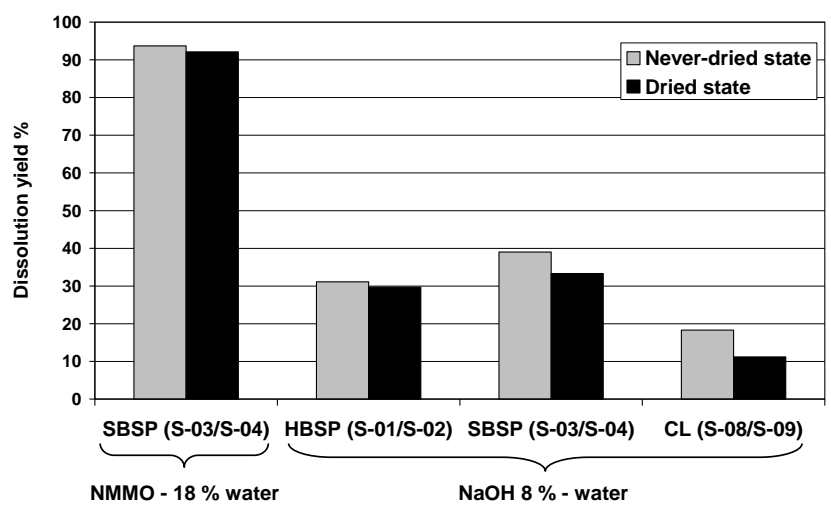

Fig. 3 


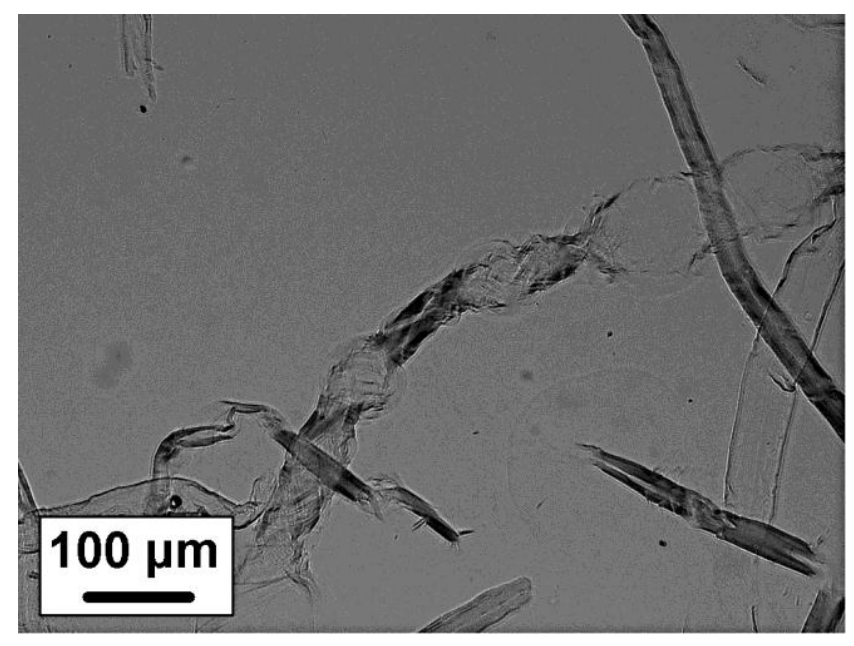

Fig. 4

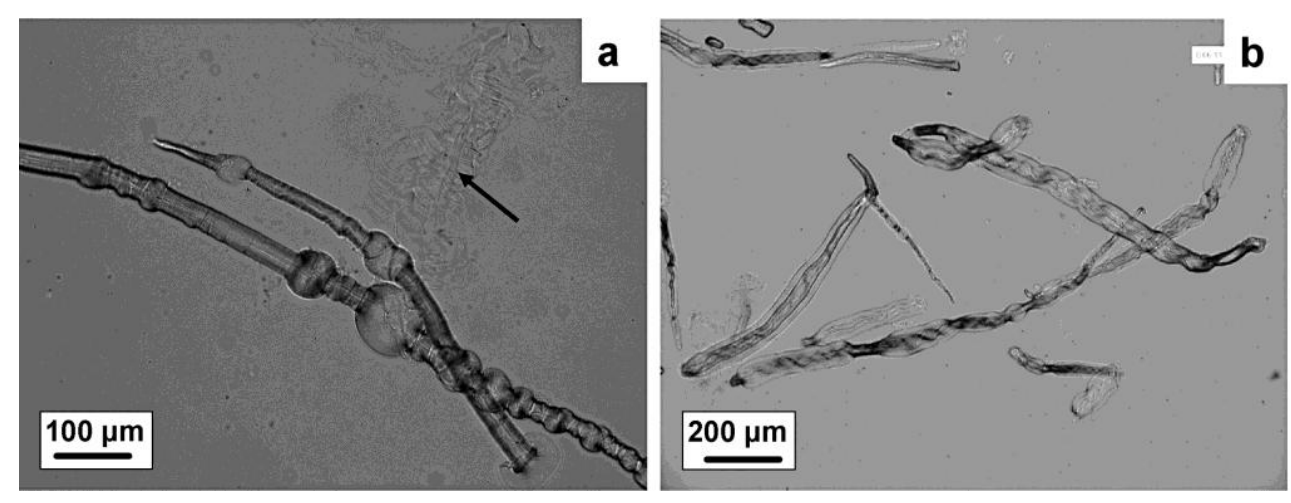

Fig. 5 